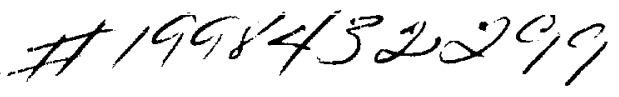

J. Quant. Spectrosc. Radiat. Transer Vol. 60. No. 5, pp. $903-919,1998$ Published by Elsevier Science Lid

\title{
ATMOS/ATLAS 3 INFRARED PROFILE MEASUREMENTS OF CLOUDS IN THE TROPICAL AND SUBTROPICAL UPPER TROPOSPHERE
}

\author{
C. P. RINSLAND, †t M. R. GUNSON,\$ P.-H. WANG, $\|$ R. F. ARDUINI, \\ B. A. BAUM,$\dagger$ P. MINNIS, $\dagger$ A. GOLDMAN, $\ddagger \ddagger$ M. C. ABRAMS, $\$$ R. ZANDER, $\|$ \\ E. MAHIEU, \|\| R. J. SALAWITCH,\$ H. A. MICHELSEN, $\|$ F. W. IRION $\S$ and \\ M. J. NEWCHURCH+++ \\ $†$ Atmospheric Sciences Division, NASA Langley Research Center, Hampton, Viginia 23681, U.S.A.; §Jet \\ Propulsion Laboratory, California Institute of Technology, 4800 Oak Grove Drive, Mail Stop 183-301, \\ Pasadena, CA 91109, U.S.A.; \|Science and Technology Corporation, 101 Research Drive, Hampton, VA \\ 23666, U.S.A.; - Science Applications International Corporation, I Enterprise Parkway, Suite 300, Ham- \\ pton, VA 23666, U.S.A.; ++ + Department of Physics, University of Denver, Denver, CO 80208, U.S.A.; \$ ITT \\ Defense and Electronics, 1919 W. Cook Road, P. O. Box 3700, Fort Wayne, IN 46801, U.S.A.; || ||Institute \\ of Astrophysics, University of Liège, Liège-Cointe, Belgium: Harvard University, Division of Applied \\ Sciences, 12 Oxford Street, Cambridge, MA 02138, U.S.A, and $¥+\ddagger$ Department of Atmospheric Science, \\ University of Alabama in Huntsville, Huntsville, AL 35899, U.S.A.
}

(Received 12 May 1997; revised 8 January 1998)

\begin{abstract}
Vertical profiles of infrared cirrus extinction have been derived from tropical and subtropical upper tropospheric solar occultation spectra. The measurements were recorded by the Atmospheric Trace Molecule Spectroscopy (ATMOS) Fourier transform spectrometer during the Atmospheric Laboratory for Applications and Sciences (ATLAS) 3 shuttle flight in November 1994. The presence of large numbers of small ice crystals is inferred from the appearance of broad extinction features in the $8-12 \mu \mathrm{m}$ region. These features were observed near the tropopause and at lower altitudes. Vertical profiles of the ice extinction $\left(\mathrm{km}^{-1}\right)$ in microwindows at 831,957 , and $1204 \mathrm{~cm}^{-1}$ have been retrieved from the spectra and analyzed with a model for randomly oriented spheroidal ice crystals. An area-equivalent spherical radius of $6 \mu \mathrm{m}$ is estimated from the smallest ice crystals observed in the $8-12 \mu \mathrm{m}$ region. Direct penetration of clouds into the lower stratosphere is inferred from observations of cloud extinction extending from the upper troposphere to $50 \mathrm{mbar}(20 \mathrm{~km}$ altitude). Cloud extinction between 3 and $5 \mu \mathrm{m}$ shows very little wavelength dependence, at least for the cases observed by the ATMOS instrument in the tropics and subtropics during ATLAS 3. Published by Elsevier Science Ltd.
\end{abstract}

\section{INTRODUCTION}

The frequent occurrence of subvisible cirrus clouds in the tropical upper troposphere ${ }^{1-4}$ is of interest because of the potential impact of these clouds on the Earth's radiation budget. Although they only slightly increases the albedo, subvisual cirrus can cause a net warming on the order of $1 \mathrm{Wm}^{-2.4}$ This effect is small if considered only at a single time or location, but it is important because of the persistence of these clouds. Thin cirrus IR extinction in the tropopause region may increase the local heating rate by a few Kelvin per day, ${ }^{5.6}$ resulting in local radiative energy absorption and vertical motion that may be in part responsible for lower stratospheric circulation. ${ }^{6}$ Furthermore, the formation of these clouds may play a role in the freeze drying of air as it is lofted into the tropical lower stratosphere. ${ }^{7}$ Efficient reactions of $\mathrm{ClONO}_{2}$ with $\mathrm{HCl}$ and $\mathrm{H}_{2} \mathrm{O}$, and $\mathrm{HOCl}$ with $\mathrm{HCl}$, are likely to take place on the surfaces of cirrus clouds ${ }^{8}$ and persistently perturb chlorine chemistry near the tropical tropopause, though the changes predicted are small in absolute terms because of the low inorganic chlorine abundance. ${ }^{9}$

$\ddagger$ To whom all correspondence should be addressed. 
In situ observational information on the microphysical properties of ice crystals in tropical upper tropospheric cirrus is very limited because these clouds are relatively inaccessible, and it is difficult to detect and reliably measure the sizes and shapes of small ice crystals $(<25 \mu \mathrm{m})$ with probes. Despite considerable scatter, the published in situ measurements ${ }^{11-14}$ show a general decrease in size with decreasing temperature, with a large number of small crystals observed in the cold tops of tropical cumulonimbus systems. Small ice crystals sampled near K wajalein, Marshall Island, and near Nadi, Fiji, made up more than half the mass and caused more th $\mathrm{tn}$ half the extinction in the upper, colder parts of the cirrus. ${ }^{11}$ Knollenberg et al ${ }^{12}$ noted that the ice crystals in tropical anvils associated with tropical cyclones over Micronesia were much smaller than those observed in tropical anvils at slightly warmer temperature over Panama. ${ }^{14}$ Mean mass equivalent sizes of $20-40 \mu \mathrm{m}$ were measured near the cold cloud tops over Micronesia. ${ }^{12}$ Knc llenberg et al ${ }^{12}$ further noted that the ice crystals they observed at very low temperatures were deuse and quasi-spherical or of low aspect ratio, whereas Hemysfield and McFarquhar ${ }^{11}$ noted pr marily columns at temperatures below $-50{ }^{\circ} \mathrm{C}$. The variety may be due to both natural variabilit $y$ and differences in the sensitivities of the instrumentation.

The ice density in cirrus near the tropical tropopause is over 50 times the water vapour density. ${ }^{12}$ Lidar observations have shown that a narrow $(<1 \mathrm{~km}$ ve tical thickness) subvisible cirrus layer is persistent near the tropical tropopause with backtrajectory calculations indicating that this layer originates in convective cloud systems. ${ }^{7}$ Passive spaceborne instruments have also been used to study tropical high altitude cirrus. Microphysical properties have been inferred from observations by nadir-viewing infrared imagers ${ }^{15-17}$ and the Infrared Interferometer Spectrometer (IRIS) flown on the Nimbus 4 meteorological satellite in $1970 .{ }^{18}$ Nadir-viewing instruments provide good spatial and temporal sampling, but very limited ve:tical information. Limb-viewing instruments have the advantages of high vertical resolution and sensitivity, but with poorer spatial and temporal sampling. To date, the only limb observations analyzed to derive the frequency of occurrence and microphysical properties of high altitıde thin cirrus are the visible and near infrared solar occultation observations recorded by the Stı atospheric Aerosol and Gas Experiment (SAGE) II instrument. ${ }^{2,4}$ Assuming spherical particles and Mie theory, Wang et al ${ }^{2}$ concluded that the SAGE II measurements contain information on particles with radii between about 0.1 and $1.0 \mu \mathrm{m}$. The SAGE II tropical high cloud data reveal varying ratios between the extinction at 0.525 and $1.02 \mu \mathrm{m}$, which have been interpreted as indicating ice particle growth during cirrus cloud evolution.

The purpose of this paper is to report an initial study of ing spectral and high vertical resolution infrared solar occultation spectra of tropical and northerr hemisphere subtropical ice clouds. The measurements were obtained from low Earth orbit with tre Atmospheric Trace Molecule Spectroscopy (ATMOS) Fourier transform spectrometer (FTS) dı ring its final shuttle flight in November 1994. We focus here on the analysis of spectra recorded $w$ th filters covering $625-1400 \mathrm{~cm}^{-1}$ (filter 12) and $1550-3420 \mathrm{~cm}^{-1}$ (filter 3). An accompanying pape ${ }^{.19}$ presents an analysis of the same data set for the volume mixing ratio profiles of several relativ sly long-lived trace gases. In this work, a brief description of the tropical and subtropical FTS measurements is presented in Sec. 2. In Sec. 2.1, filter 12 high and low Sun spectra are illustrated for clear sky conditions and an observation through a thin cirrus cloud with a high density of small ice crystals. The method used to retrieve vertical cirrus extinction profiles at selected narrow spect al regions is described and examples of multi-wavelength vertical cirrus extinction profiles are pesented. Section 2.2 presents a similar discussion and results from the filter 3 observations. In Sec 3, we report the comparison of selected cirrus extinction profiles with calculated values generated $\mathrm{w}$ ith a model developed for simulating the infrared radiative properties of spheroidal and hexagonal ice crystals. ${ }^{17}$ The measurements are compared with model results calculated for spherical pirticles and spheroids. Finally, the key conclusions and unresolved questions are summarized in jec. 4.

\section{ATMOS ATLAS 3 TROPICAL AND SUBTF OPICAL OBSERVATIONS}

The ATMOS FTS recorded broadband $0.01 \mathrm{~cm}^{-1}$ resclution mid-IR solar occultation spectra during 4 Shuttle flights. ${ }^{20,21}$ Two-sided interferograms with a maximum optical path difference of $47 \mathrm{~cm}$ were obtained at $2.2 \mathrm{~s}$ intervals during sunrises or s insets and Fourier transformed to yield 
Table 1. ATMOS/ATLAS 3 occultations analyzed in this study

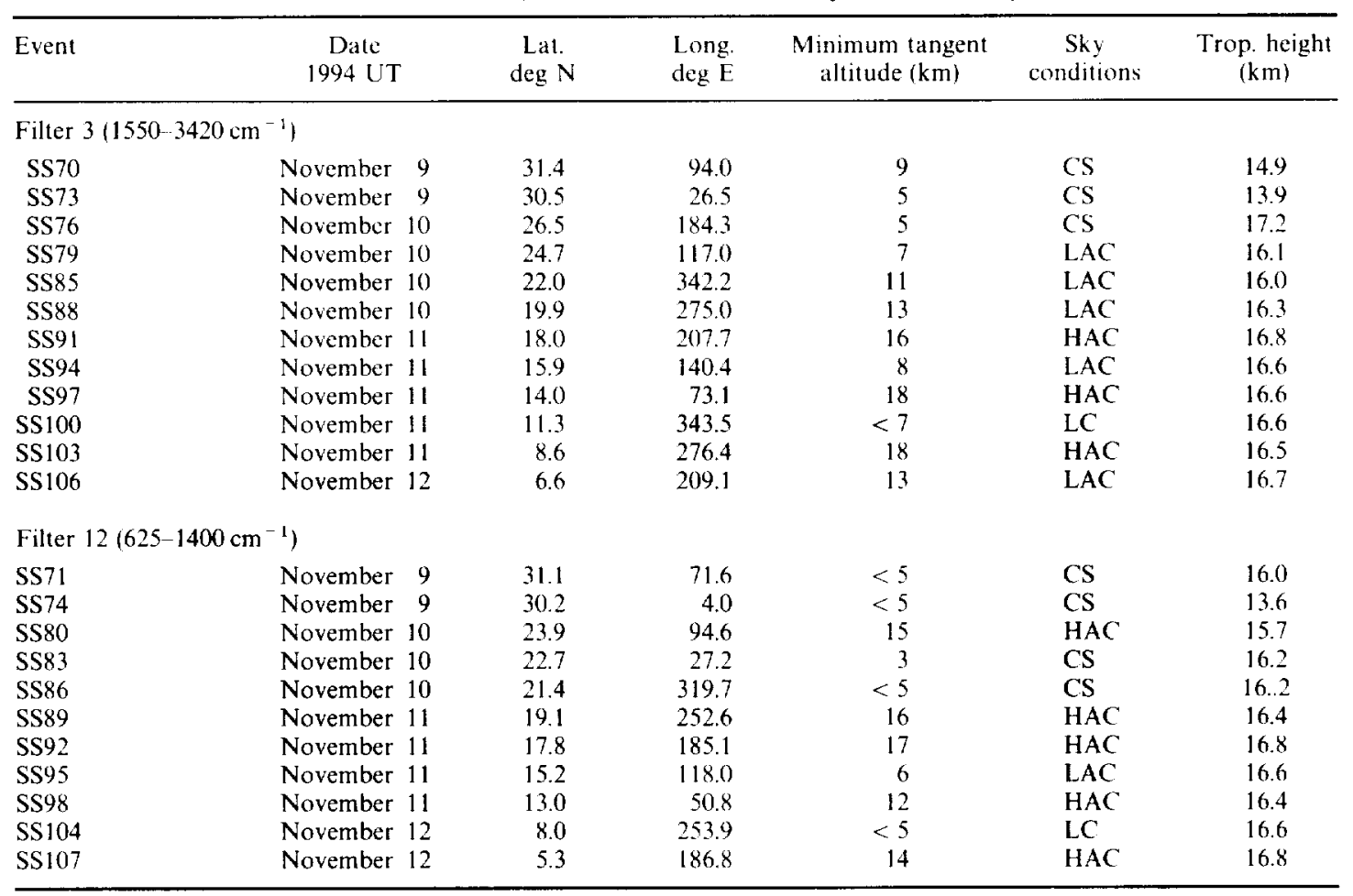

Note: Latitude (Lat.) and longitude (Long.) at the tangent point for the spectrum nearest to a tangent altitude of $15 \mathrm{~km}$. SS-sunset. Qualitative classification of upper tropospheric measurements: CS-clear sky; HAC-high altitude cirrus (maximum altitude $>15 \mathrm{~km}$ ); LAC-low altitude cirrus (maximum altitude $<15 \mathrm{~km}$ ); LC-layered cirrus. Tropopause (Trop.) heights are from NMC data ${ }^{4.5}$.

series of exoatmospheric (pure solar) and low Sun (atmospheric) spectra below a tangent aititude of $\sim 150 \mathrm{~km}$. A two-axis servo-controlled suntracker was used to position the sensor field of view on the Sun during the $4 \mathrm{~min}$ of observations during each occultation event. Overlapping optical bandpass filters limited the total spectral coverage to 625 to $4750 \mathrm{~cm}^{-1}$. The results reported in this work were recorded during the Atmospheric Laboratory for Applications and Science (ATLAS) 3 mission (3-12 November 1994) $)^{22}$ with ATMOS filter 12 covering $625-1400 \mathrm{~cm}^{-1}$ at a signal to root-mean-square (rms) noise ratio of $\sim 100$. Each low Sun spectrum was divided by an average of exoatmospheric spectra from the same occultation to remove solar features, lines of $\mathrm{H}_{2} \mathrm{O}$ and $\mathrm{CO}_{2}$ from residual air within the interferometer, and the wavelength dependence of the instrument-filterdetector system response.

ATMOS FTS atmospheric observations during the ATLAS 3 mission were recorded during 107 sunsets with tangent point latitudes between $5^{\circ} \mathrm{N}$ and $49 \mathrm{~N}$ and 94 sunrises with tangent point latitudes of $64^{\circ} \mathrm{S}$ to $72^{\circ} \mathrm{S}^{23}$ Tropical and subtropical measurements, the focus of this paper, were obtained late in the mission at relatively high beta angles. The refracted tangent height spacings of successive late mission observations $(\sim 1 \mathrm{~km}$ near the tropopause) were one-half to one-third the typical ATMOS value. The effective vertical resolution of the observations was limited principally by the finite scan time and the circular instrumental field of view on the Sun: $1.0 \mathrm{mrad}$ in diameter (2.0 km at the tangent point) for filter 3 observations and $2.0 \mathrm{mrad}$ in diameter $(4.0 \mathrm{~km}$ at the tangent point) for filter 12 observations. The range in tangent point latitude and longitude sampled during a tropical occultation varied significantly during the event but did not exceed 2 between tangent heights of 15 and $30 \mathrm{~km}$. Table 1 provides a list of the tropical and subtropical occultations analyzed in this study. Papers by Norton and Rinsland ${ }^{24}$ and Abrams et al ${ }^{25}$ provide a description of the ATMOS data-processing methods which have been applied primarily to retrieve stratospheric and mesospheric molecular volume mixing ratio and pressure-temperature profiles from microwindows in the spectra. The accompanying paper ${ }^{19}$ describes the method used to determine tangent pressures 
and volume mixing ratio profiles of several molecules from the upper tropospheric spectra analyzed in this work.

\subsection{Filter 12 spectra}

Figure 1 shows examples of the 8-12 $\mu \mathrm{m}$ window region in tropical spectra recorded with filter 12 . Each spectrum has been normalized to the peak signal in the interval. The upper panel presents
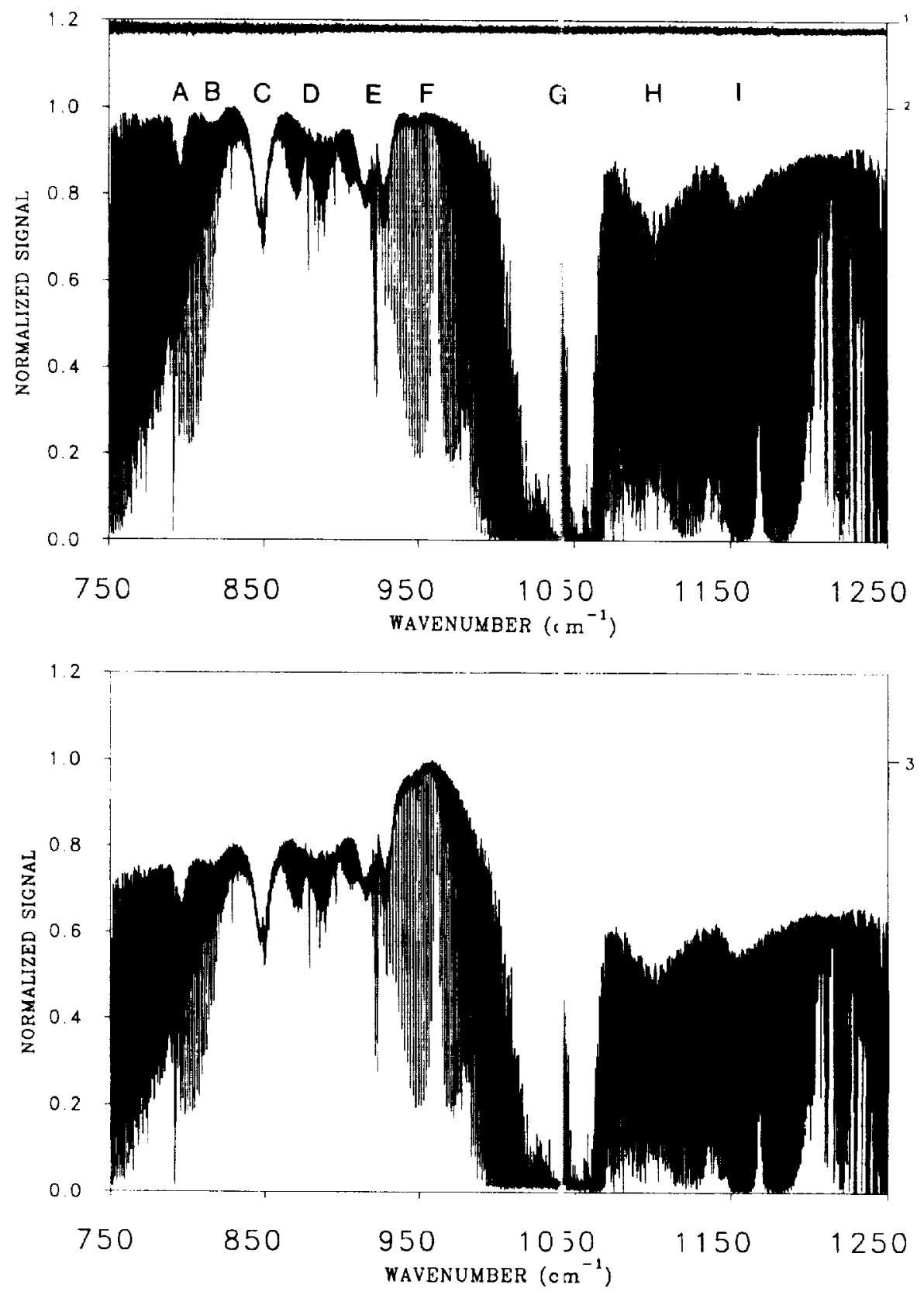

Fig. 1. Examples of the 8-12 $\mu \mathrm{m}$ region in ATMOS tropical filte $\cdot 12$ spectra. Each spectrum is normalized to the highest signal in the interval. The upper spectrum in the tol panel is offset vertically by 0.2 for clarity. Upper panel, scan I: high Sun spectrum from SS104 recorded it a tangent pressure of $2.83 \times 10^{-4} \mathrm{mbar}$ $(100.0 \mathrm{~km}$ tangent height). Upper panel, scan 2: upper troposph ric spectrum from SS104 recorded under nearly clear sky conditions. The pressure, altitude, and temperc ture at the tangent point were $104.0 \mathrm{mb}$, $16.3 \mathrm{~km}$, and $198.2 \mathrm{~K}$, respectively. Locations of prominent mole ular absorption features are marked with letters. See text for identifications. Lower panel, scan 3: SS107 sp:ctrum recorded through a tropical cirrus (ice) cloud. The pressure, altitude, and temperature at the tangent point were $103.3 \mathrm{mb}, 16.3 \mathrm{~km}$, and $197.4 \mathrm{~K}$, respectively. 
observations recorded during occultation SS104 (SS-sunset). The tangent pressures (heights) of the scans are $2.83 \times 10^{-4} \mathrm{mbar}(100.0 \mathrm{~km})$ and $104.0 \mathrm{mbar}(16.3 \mathrm{~km})$, respectively. No significant absorption features appear in the upper scan, which illustrates the high signal-to-noise of the observations and the success achieved in removing instrumental and solar features from this spectrum. The low Sun spectrum was recorded under nearly clear sky conditions. Nine prominent molecular absorption features are marked above the spectrum: (A) identifies the $794 \mathrm{~cm}^{-1} v_{3}$ band of $\mathrm{CCl}_{4}$; (B) the $809 \mathrm{~cm}^{-1} v_{7}$ band of $\mathrm{CHClF}_{2}$ (HCFC-22); (C) the $846 \mathrm{~cm}^{-1} v_{4}$ band of $\mathrm{CCl}_{3} \mathrm{~F}$ (CFC-11); (D) the overlapping $879 \mathrm{~cm}^{-1} v_{5}$ and $897 \mathrm{~cm}^{-1} 2 v_{9}$ bands of $\mathrm{HNO}_{3} ;(\mathrm{E})$ the $923 \mathrm{~cm}^{-1} v_{5}$ band of $\mathrm{CCl}_{2} \mathrm{~F}_{2}$ (CFC-12); (F) the $960 \mathrm{~cm}^{-1}$ (00011) (10001) band of $\mathrm{CO}_{2}$, (G) the $1042 \mathrm{~cm}^{-1} v_{3}$ band of $\mathrm{O}_{3}$; (H) the $1102 \mathrm{~cm}^{-1} v_{1}$ band of $\mathrm{CCl}_{2} \mathrm{~F}_{2}$; and (I) the $1161 \mathrm{~cm}^{-1} v_{8}$ band of $\mathrm{CCl}_{2} \mathrm{~F}_{2}$. This spectral region also contains absorption by weaker bands of the molecules noted above plus significant absorptions by additional molecules, particularly $\mathrm{N}_{2} \mathrm{O}, \mathrm{CH}_{4}, \mathrm{H}_{2} \mathrm{O}$, and $\mathrm{SF}_{6}$.

The lower panel of Fig. 1 shows a normalized spectrum recorded during occultation SS107. The pressure and temperature at the tangent point are nearly the same as the values for the low Sun spectrum from SS104. The molecular features in the SS104 and SS107 low Sun spectra have very similar absorption depths. However, the molecular bands in $\mathrm{SS} 107$ are superimposed on additional broad extinction features. A distinct feature with a maximum is observed at $955 \mathrm{~cm}^{-1}$. This feature has been observed previously in ground-based, ${ }^{26}$ nadir-view aircraft, ${ }^{27-29}$ and IRIS-D satellite nadir-view emission FTS spectra in equatorial ${ }^{1}$ and polar regions. ${ }^{30}$ The peaked spectral shape has been reported previously for this feature only for nadir observations in polar regions during the winter and the early spring. ${ }^{30}$ Extinction by this feature increases again above $960 \mathrm{~cm}^{-1}$, but the wavelength dependence is difficult to quantify between 960 and $1080 \mathrm{~cm}^{-1}$ because of strong absorption by the $\mathrm{O}_{3} v_{3}$ band. The normalized signal between 1080 and $1250 \mathrm{~cm}^{-1}$ is also significantly lower in SS107 than in SS104. The additional extinction in this region is overlapped by moderately strong molecular absorption by several molecules.

As noted in previous studies, ${ }^{26-29}$ the spectral properties of the additional, broad extinction observed in SS107 but not in SS104 can be attributed to small water ice and/or liquid water particles in optically thin cirrus clouds. Ice crystals can be expected at the low temperatures near the tangent point of the SS107 observations. This extinction cannot be explained by the presence of sulfate aerosol $\left(\mathrm{H}_{2} \mathrm{SO}_{4}+\mathrm{H}_{2} \mathrm{O}\right)$ droplets, which have a much different wavelength dependence in the $8-12 \mu \mathrm{m}$ region. ${ }^{31}$ Although $\mathrm{HNO}_{3}$ is soluble in water and has been predicted to condense with water as nitric acid trihydrate (NAT) at temperatures slightly above the frost point, calculations of aerosol composition made with an equilibrium model indicate that $\mathrm{HNO}_{3}$ plays only a minor role in the crystal nucleation in the tropical upper troposphere because of the low concentration of $\mathrm{HNO}_{3}$ vapour. ${ }^{5}$ Furthermore, as demonstrated by a recent reanalysis ${ }^{32}$ of the infrared spectra of type I polar stratospheric clouds (PSCs) observed over Antarctica in September 1987, ${ }^{33}$ the role of $\mathrm{HNO}_{3}$ in low temperature cloud formation is unclear; the observed infrared spectral features do not match synthetic spectra computed for NAT and other suspected compositions. A more complex, but unknown composition is likely ${ }^{32}$ for the aerosols in these low temperature, nitrogen-enriched clouds. $^{34}$

Window measurements at 8,11 , and $12 \mu \mathrm{m}$ are useful for distinguishing between ice water and liquid water clouds ${ }^{29}$ and quantifying the sizes and shapes of small ice crystals in cirrus. ${ }^{15-17,26-29}$ Therefore, cloud extinction was quantified from measurements in narrow window regions near these three wavelengths. The signals from the full set of filter 12 tropical observations were first plotted versus tangent pressure. The highest signals at the three wavelengths form a compact relation vs tangent pressure which was least-squares fitted and assumed to represent clear sky conditions. The signal defined by this curve varies with tangent pressure because of the nonlinear response of the ATMOS HgCdTe photoconductive detector at the high incident solar flux. ${ }^{35}$ About half of the observations below the tropopause have signals lower than the reference curve. We assume that the low signals are the result of cloud extinction along the measurement line of sight.

Figure 2 shows the residuals calculated from the difference between the clear sky reference curves and measurements from occultations SS71, SS74, and SS104. The residuals for $830.75-831.00 \mathrm{~cm}^{-1}$ are presented in the left panel. Hereafter, this interval is called the $831 \mathrm{~cm}^{-1}$ window. Laboratory measurements between 100 and $266 \mathrm{~K}$ indicate that the imaginary index of refraction of hexagonal ice has a peak near this wavelength ${ }^{36-40}$ Line-by-line radiative transfer calculations with a realistic 

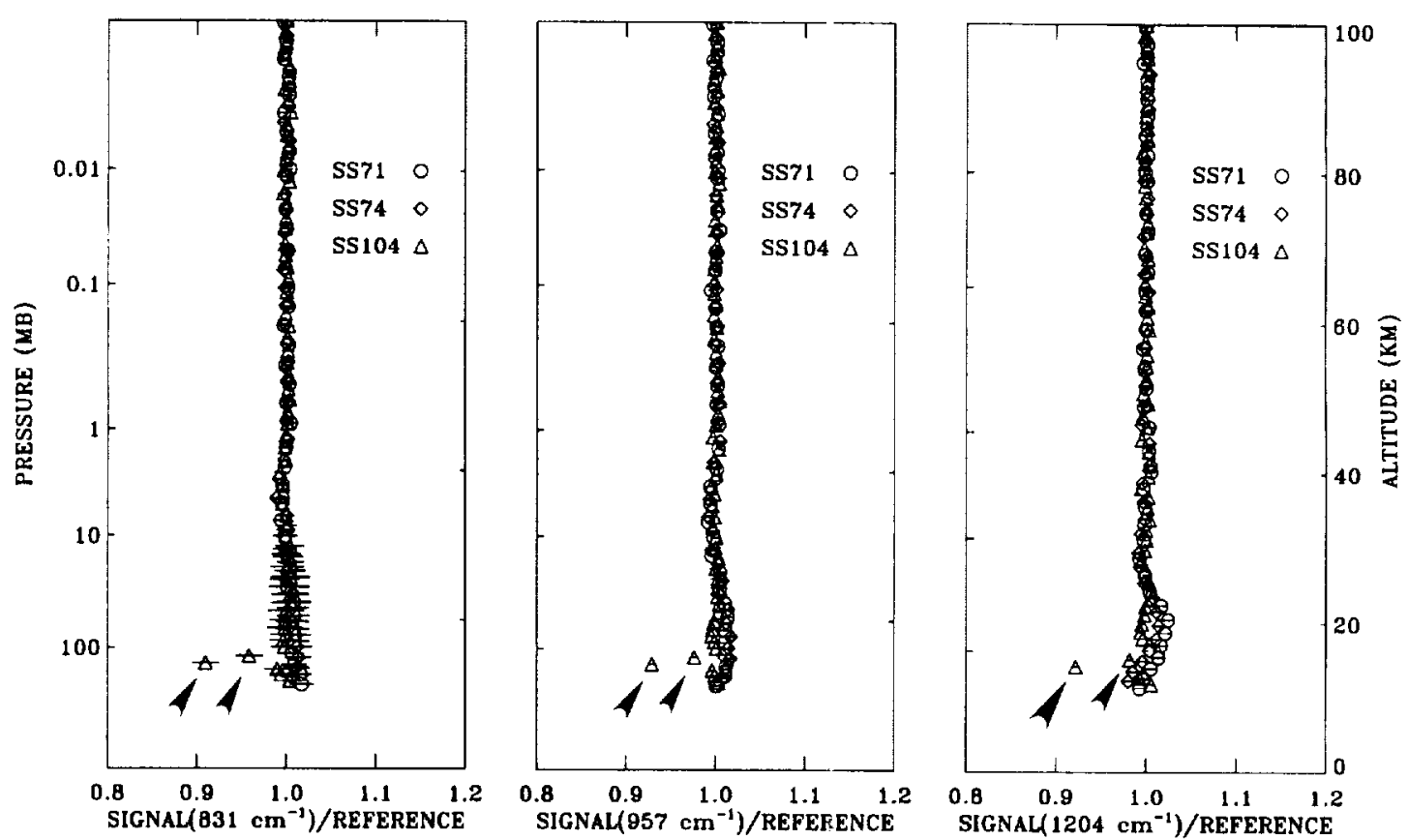

Fig. 2. Signals measured in the 831,957 , and $1204 \mathrm{~cm}^{-1}$ windows divided by the corresponding clear sky reference curve. The observations were recorded under nearly optically clear sky conditions during occultations SS71, SS74, and SS104. Arrow heads mark two low yalues from optical thin cirrus measured in the tropopause region. Error bars show standard deviations of the values.

set of gas mixing ratio profiles and the molecular paramett $r$ from the 1995 ATMOS line list ${ }^{41}$ and the 1996 HITRAN compilation ${ }^{42}$ (lines and absorption cross sections included from both databases) predict a transmittance of 0.98 for limb paths above a tangent pressure of $150 \mathrm{mbar}$ ( $14 \mathrm{~km}$ altitude). The measurements marked with arrowheads show the extinction by an optically thin cirrus layer in SS104 with a vertical thickness of $\sim 1 \mathrm{~km}$ near the tropical tropopause. ${ }^{5.6}$ As shown, this same extinction feature appears in the residuals for $956.70-957.00 \mathrm{~cm}^{-1}\left(957 \mathrm{~cm}^{-1}\right.$ window) and $1204.40-1204.55 \mathrm{~cm}^{-1}\left(1204 \mathrm{~cm}^{-1}\right.$ window). Radiative transfer calculations with known molecular lines, absorption cross sections, and a reference set of vertical gas concentration profiles predict a transmittance of 0.99 and 0.97 above $150 \mathrm{mbar}$ ( $14 \mathrm{~km}$ alitude) for these two windows, respectively. Comparison of the clear sky signal profiles from the $204 \mathrm{~cm}^{-1}$ window with those from the windows at 831 and $957 \mathrm{~cm}^{-1}$ confirms that extinction it the $1204 \mathrm{~cm}^{-1}$ window is greater than corresponding values in the other two windows. However, the measured signals at $1204 \mathrm{~cm}^{-1}$ are lower than those at 831 and $957 \mathrm{~cm}^{-1}$ by $\sim 13 \%$ at 150 mbar, which suggests the presence of significant, unmodeled upper tropospheric extinction in $:$ he $1204 \mathrm{~cm}^{-1}$ region. We assume that molecular and other non-cloud sources of extinction in all three windows have been removed to first order by dividing the signal measured in the window by th : corresponding value from the clear sky vs pressure reference curve. Based on the residuals in Fig. 2, the 1-sigma precisions in defining the clear sky reference curves at 831,957 , and $1204 \mathrm{~cm}^{-1}$ in th: troposphere and lower stratosphere are estimated as 3,3, and 5\%, respectively. A major sulfate a rosol band has its peak extinction near $1190 \mathrm{~cm}^{-1} \cdot{ }^{31}$ Hence, significant aerosol extinction will oc sur in the $1204 \mathrm{~cm}^{-1}$ window over limb paths with high aerosol loadings.

Cloud transmittances, calculated by dividing the measured signals by the clear sky reference curve, were converted to optical depths and then analyzed to derive vertical profiles of cloud extinction $\left(\mathrm{km}^{-1}\right)$ at the wavelengths of the three windows. An onion-peeling inversion procedure was adopted assuming a spherically symmetric atmosp iere. Hence, cloud extinction over the $200 \mathrm{~km}$ observation path is assumed to be only a function of the pressure altitude of the layer. Horizontal variations across the width of the field of view ind nonspherically symmetric extinction along the solar occultation ray path cannot be determined from the observations. 

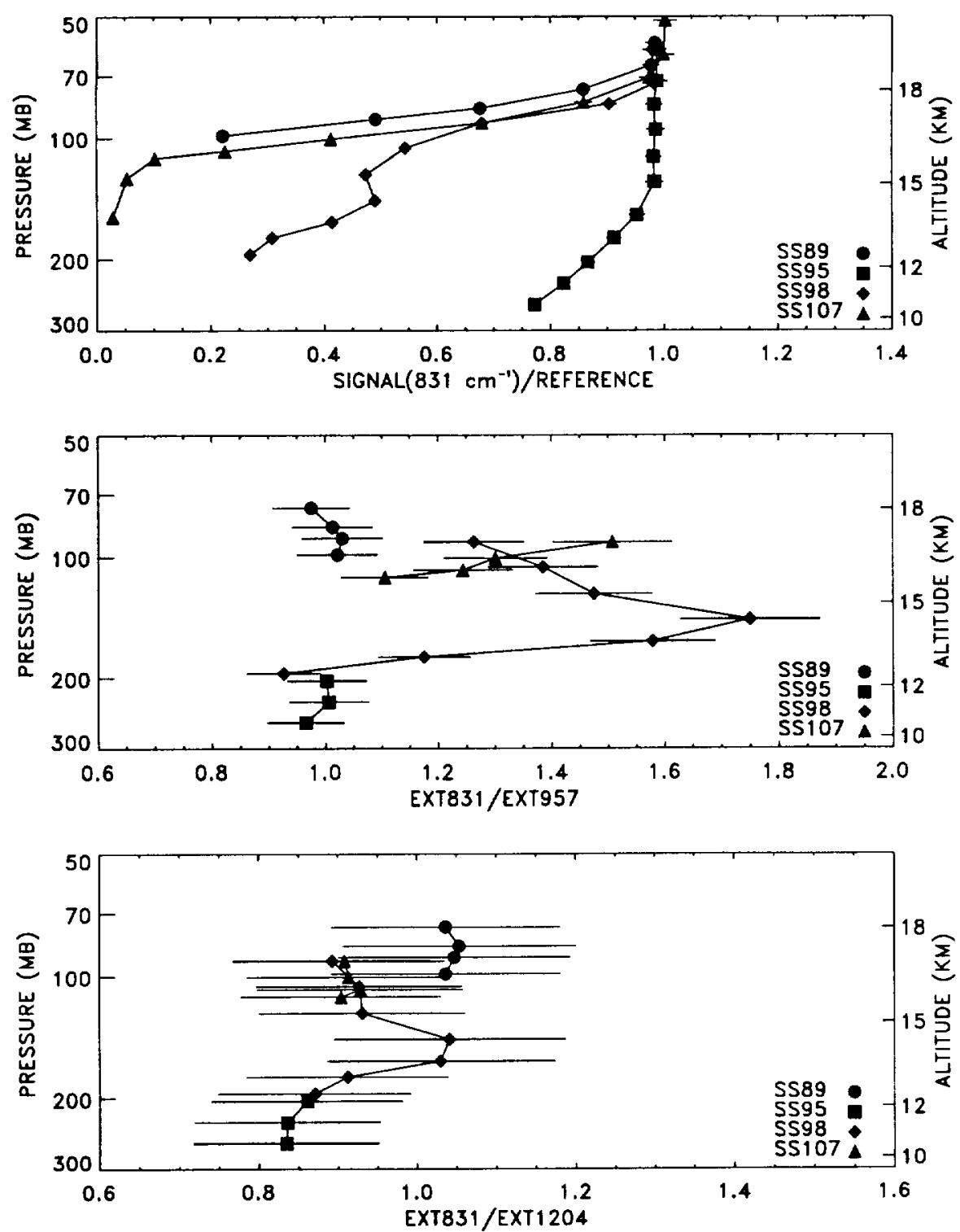

Fig. 3. Top panel: Examples of cloud transmittance profiles at $831 \mathrm{~cm}^{-1}$ calculated form the average signal at $831 \mathrm{~cm}^{-1}$ divided by the corresponding value from the clear sky reference curve. Precisions are $\pm 5 \%$, $1 \sigma$. Middle panel: Profiles of EXT831/EXT957 for the same occultations. Bottom panel: Profiles of EXT831/EXT1204 for the same occultations. Error bars are estimated $1 \sigma$ uncertainties.

The top panel of Fig. 3 presents a plot of the $831 \mathrm{~cm}^{-1}$ cloud transmission profiles from four occultations. The middle panel shows the profile of EXT(831)/EXT(957), the ratio of the cloud extinction coefficient $\left(\mathrm{km}^{-1}\right)$ at $831 \mathrm{~cm}^{-1}$ to the cloud extinction coefficient $\left(\mathrm{km}^{-1}\right)$ at $957 \mathrm{~cm}^{-1}$, retrieved from these observations. Values are plotted only for cloud transmissions at $831 \mathrm{~cm}^{-1}$ between 0.05 and 0.95 . Hence, we exclude observations of weak and strong cloud extinction, which yield larger measurement uncertainties. The high extinction measurements are also avoided because they include a component due to self-emission by the cloud. Ratios of EXT(831)/EXT(957) larger than unity are characteristic of extinction by small ice crystals. ${ }^{15-17.26-30}$ The SS107 observations indicate that small ice crystals were present in large numbers near the tropopause. During SS98, thin cirrus extinction was measured between 80 and $200 \mathrm{mbar}$ with an apparent vertical distribution of small crystals that peaked in abundance near a tangent pressure of $150 \mathrm{mbar}$ ( $14 \mathrm{~km}$ altitude). Extinction ratios near unity were measured for SS89 and SS95, suggesting that small crystals did not 
dominate the ice particle populations measured near the tropopause and at lower altitudes, respectively. The bottom panel of Fig. 3 presents measurem znts of EXT(831)/EXT(1204), the ratio of the cloud extinction coefficient at $831 \mathrm{~cm}^{-1}$ to the corres sonding value at $1204 \mathrm{~cm}^{-1}$. The differences among the measurements are small and marginally s gnificant, given the estimated error bars. The results presented in Fig. 3 illustrate the variations that occur in tropical and subtropical upper tropospheric ice cloud infrared optical properties and the advantages of high vertical and high spectral resolution for passive remote sensing cloud studies.
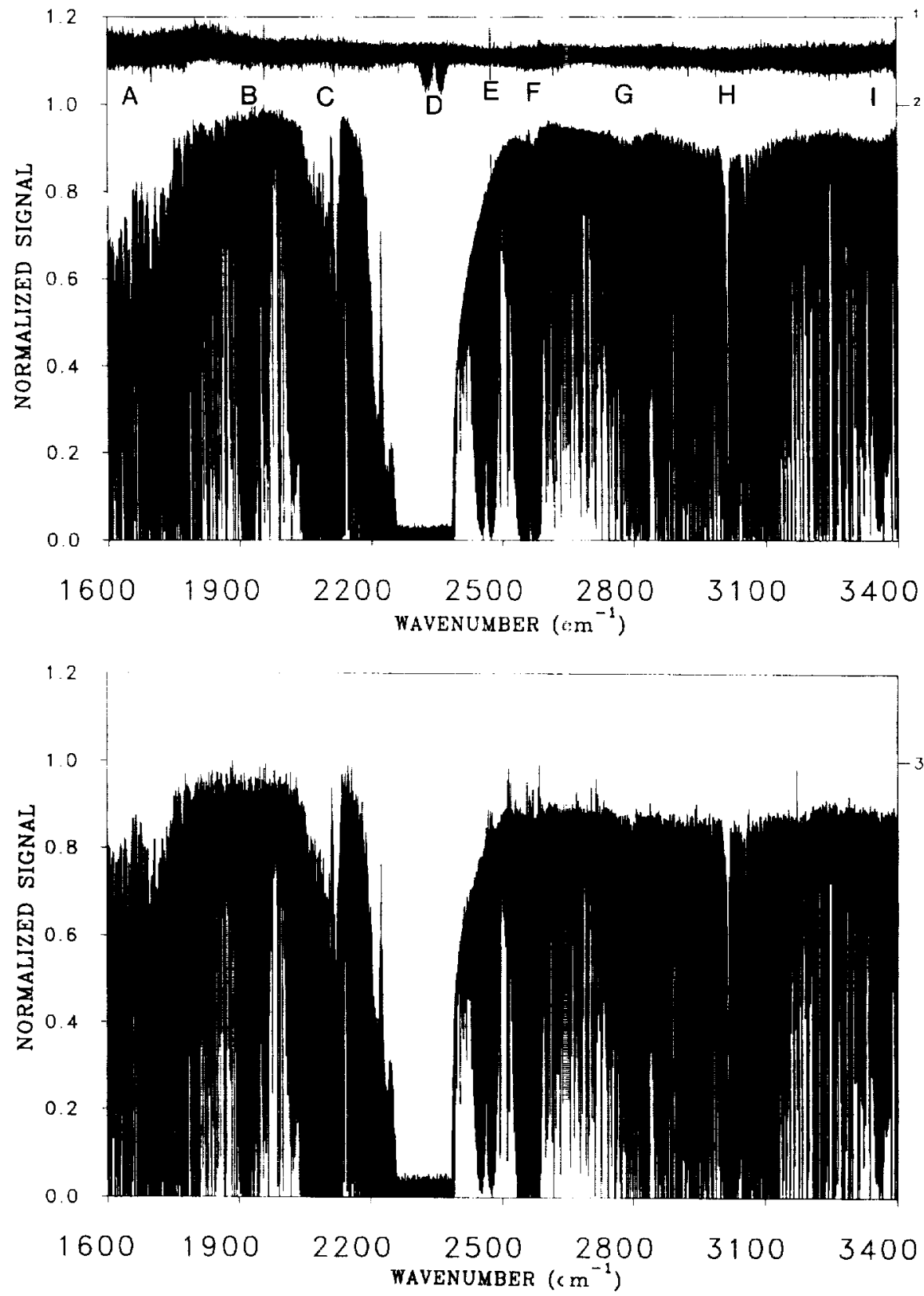

Fig. 4. Examples of the $36 \mu \mathrm{m}$ region in ATMOS tropical filter 3 spectra. Upper panel, scan 1: high Sun spectrum from SSI00 recorded at a tangent pressure of $1.31 \times 1)^{-5} \mathrm{mb}(126.7 \mathrm{~km}$ tangent height), offset vertically for clarity. Upper panel, scan 2: SS100 spectrum recor ded near the tropopause under clear sky conditions. The pressure, altitude, and temperature at the tat gent noint were $76.1 \mathrm{mb}, 18.1 \mathrm{~km}$, and 199.9 K, respectively. Prominent molecular absorption feature; are marked with letters. See text for identitications. Lower pand. scan 3: SS97 spectrum recorded in the lower stratosphere through a tropical cirrus (ice) cloud. The pressure, altitude, and temperature at the angent point were $68.1 \mathrm{mb}, 18.8 \mathrm{~km}$, and $204.1 \mathrm{~K}$, respectively. 


\subsection{Filter 3 spectra}

Figure 4 presents plots of high and low Sun ATLAS 3 tropical spectra recorded with ATMOS filter 3. The measurements in the upper panel were obtained during occultation SS100. Spectrum 1 was recorded at tangent pressure (height) of $1.31 \times 10^{-5} \mathrm{mb}(126.7 \mathrm{~km})$. The only significant feature is the intense $v_{3}$ band of $\mathrm{CO}_{2}$ at $2349 \mathrm{~cm}^{-1}$, labeled D. Spectrum 2 was recorded under clear sky conditions at a tangent pressure (altitude) of $76.1 \mathrm{mbar}(18.1 \mathrm{~km})$. The identifications and positions of the other prominent molecular features are: (A) the wing of the intense $v_{2}$ band of $\mathrm{H}_{2} \mathrm{O}$ at $1594 \mathrm{~cm}^{-1}$; (B) the $(11102)-(00001)$ band of $\mathrm{CO}_{2}$ at $1932 \mathrm{~cm}^{-1}$; (C) the overlapping (11101)-(00001) band of $\mathrm{CO}_{2}$ at $2076 \mathrm{~cm}^{-1}$, the $v_{1}+v_{3}$ band of $\mathrm{O}_{3}$ at $2111 \mathrm{~cm}^{-1}$, the $v_{3}$ band of $\mathrm{N}_{2} \mathrm{O}$ at $2224 \mathrm{~cm}^{-1}$, and the $(1-0)$ band of $\mathrm{CO}$ at $2143 \mathrm{~cm}^{-1}$; (E) the $v_{1}+2 v_{2}^{0}$ band of $\mathrm{N}_{2} \mathrm{O}$ at $2475 \mathrm{~cm}^{-1}$; (F) the $2 v_{1}$ band of $\mathrm{N}_{2} \mathrm{O}$ at $2563 \mathrm{~cm}^{-1}$, (G) the overlapping $v_{1}+v_{2}+v_{3}$ band of $\mathrm{O}_{3}$ at $2785 \mathrm{~cm}^{-1}$ and the $v_{2}+v_{4}$ band of $\mathrm{CH}_{4}$ at $2838 \mathrm{~cm}^{-1}$; (H) the $v_{3}$ band of $\mathrm{CH}_{4}$ at $3019 \mathrm{~cm}^{-1}$; and (I) the (21102)-(00001) band of $\mathrm{CO}_{2}$ at $3339 \mathrm{~cm}^{-1}$.
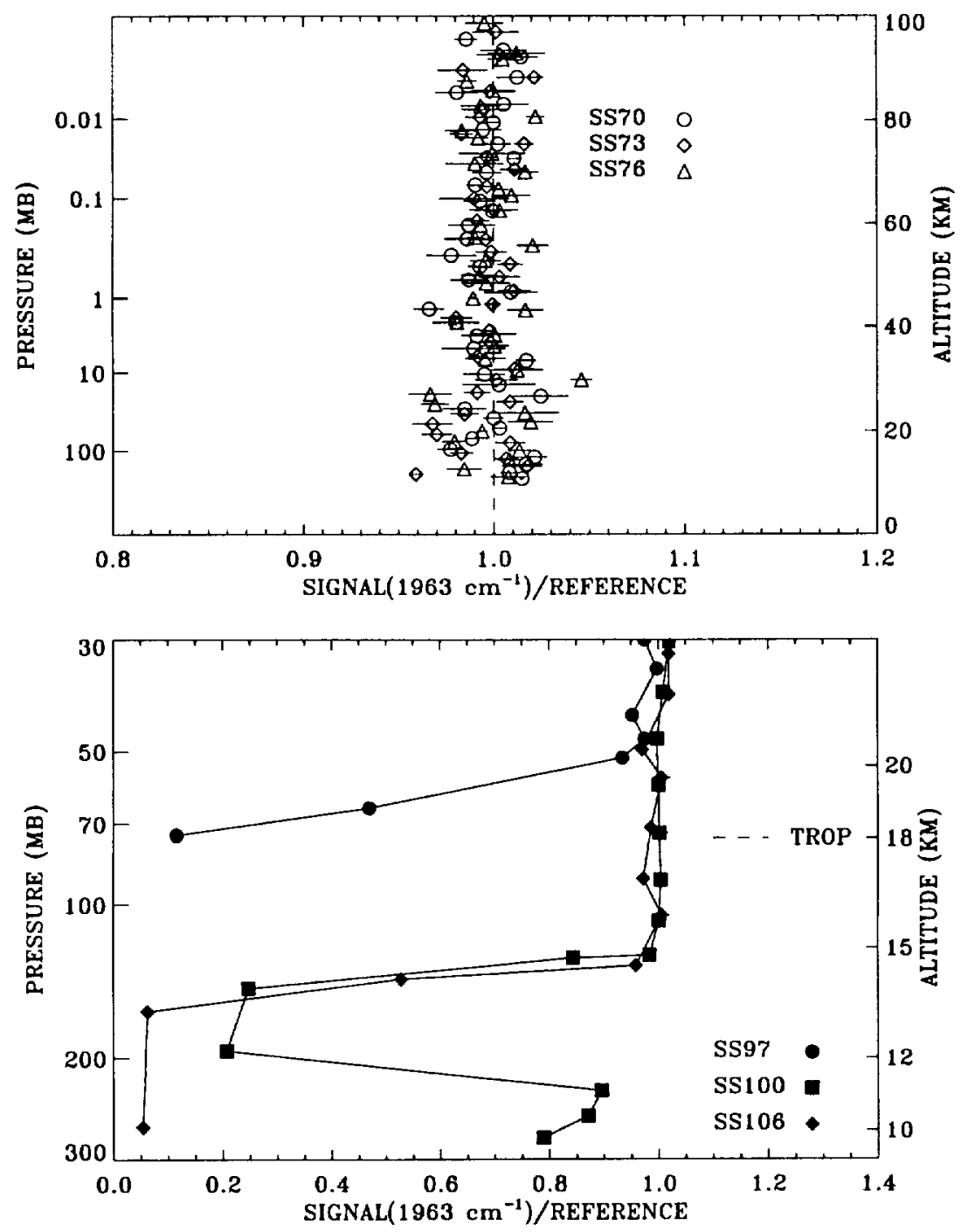

Fig. 5. Upper panel: Residuals from least-squares fits to measurements of average signal in the $1963 \mathrm{~cm}^{-1}$ window divided by the corresponding values from the empirically-determined reference curve. The measurements were recorded under optically clear sky conditions during occultations SS70, SS73, and SS76. Error bars show standard deviations of the values. Lower panel: Profiles of cloud transmission in the $1963 \mathrm{~cm}^{-1}$ window from spectra recorded during occultations SS97, SS100, and SS106. The dashed line shows the approximate altitude of the tropopause (TROP). Precisions are $\pm 5 \%, 1 \sigma$. 

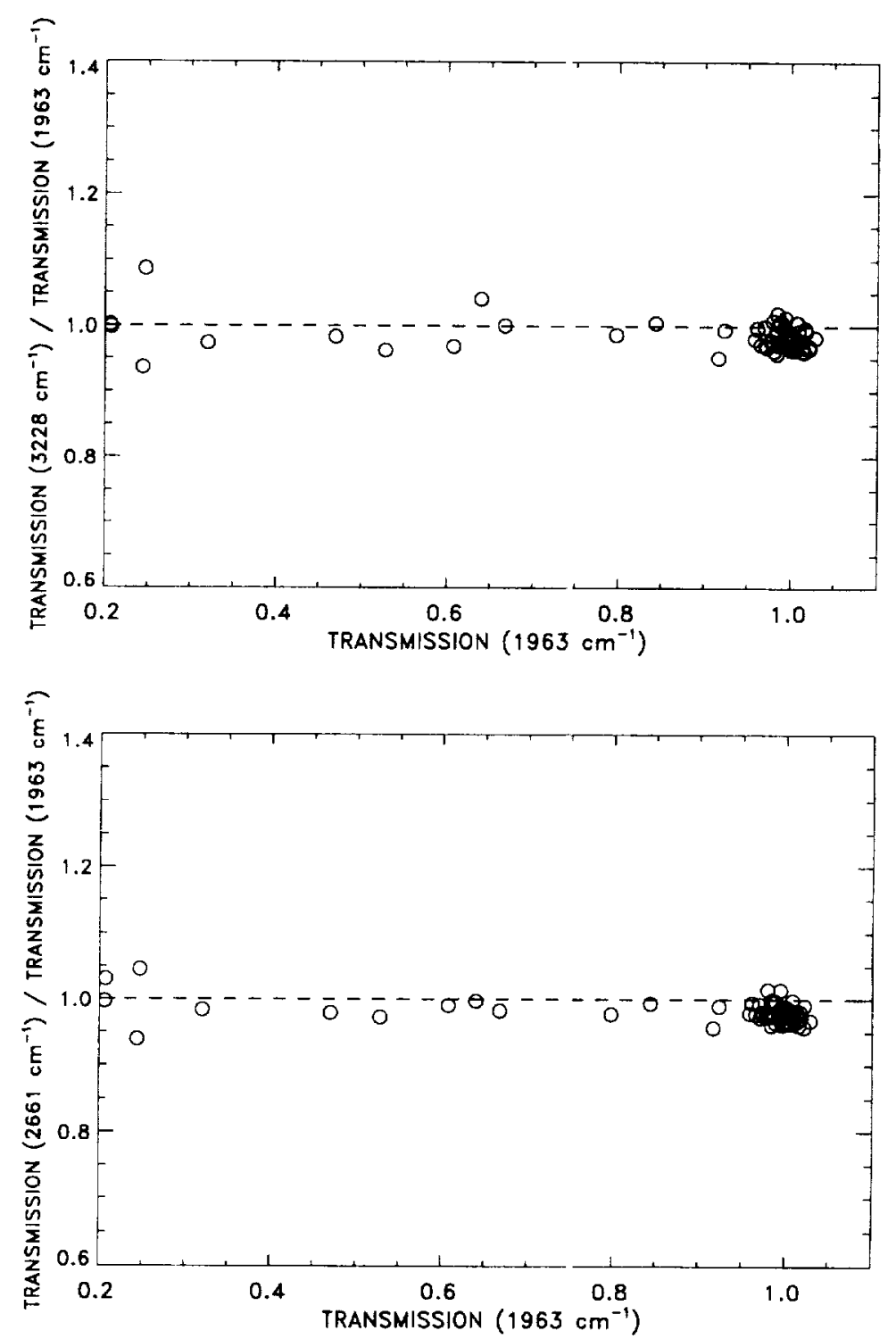

Fig. 6. Upper panel: Ratios of cloud transmittances measured in the 3228 and $1963 \mathrm{~cm}^{-1}$ windows plotted versus cloud transmittance measured in the $1963 \mathrm{~cm}^{-1}$ window. Lower panel: Ratios of cloud transmittances measured in the 2661 and $1963 \mathrm{~cm}^{-1}$ windows plotted versus the cloud transmittance measured in the $1963 \mathrm{~cm}^{-1}$ window. Tropical measurements obtained between tangent pressures of 50 and $200 \mathrm{mb}$ (12. $20 \mathrm{~km}$ altitude) have been included. Pre :isions are $\pm 5 \% .1 \sigma$.

Spectrum 3 in the lower panel of Fig. 4 was recorded through a tropical ice cloud during occultation SS97 at a tangent pressure of 68.1 mbar $(13.8 \mathrm{~km}$ tangent height). Despite strong extinction (see Fig. 5), which decreased the signal-to-noise c $f$ the spectrum, the normalized spectrum is very similar to the normalized low Sun, clear sky spect um in the upper panel. The absorption depths of the molecular bands are nearly the same, and the upper envelopes of the two spectra exhibit only minor differences in their wavelength dependeıce except for several positive "spikes" in the SS97 spectrum. These sharp features are solar lines, which appear as false emission features due to suntracker field-of-view motion in response to changing loud extinction on the lower limb of the solar disk. Spectral intervals containing these false emissio 1 features were avoided in analyzing the ATMOS measurements for cloud extinction.

Cloud transmittance profiles were measured at $1963.35-1963.40 \mathrm{~cm}^{-1}\left(1963 \mathrm{~cm}^{-1}\right.$ window), $2660.802661 .20 \mathrm{~cm}^{-1}\left(2661 \mathrm{~cm}^{-1}\right.$ window $)$, and $3228.20-3229.00 \mathrm{~cm}^{-1}\left(3228 \mathrm{~cm}^{-1}\right.$ window) with 


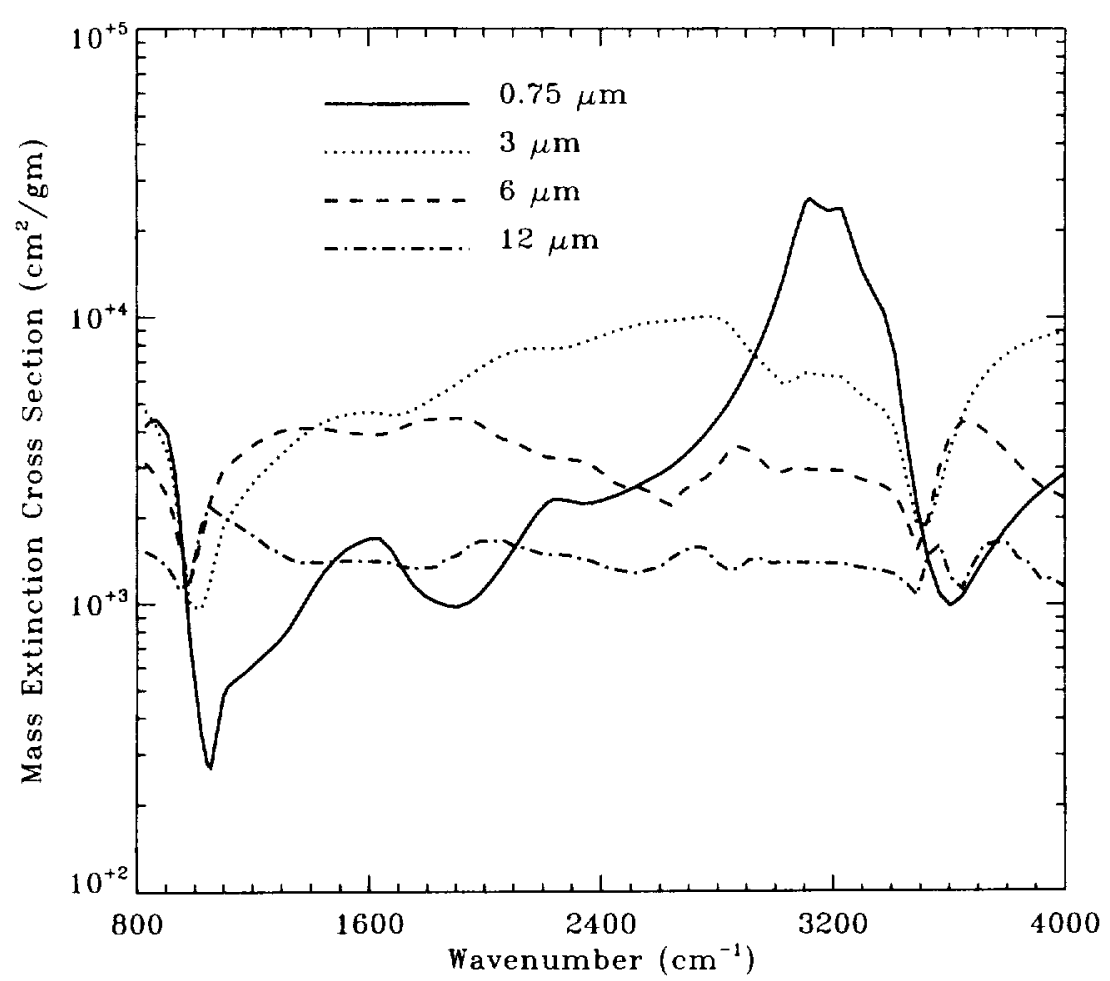

Fig. 7. Mass extinction cross sections calculated with Mie theory and the hexagonal ice crystals optical constants of Toon et al. ${ }^{39}$ The assumed particle sizes are indicated in the legend.

the method described in Sec. 2.1. Line-by-line calculations of molecular absorption with a realistic set of volume mixing ratio profiles predict clear sky transmittances $>0.99$ in these windows above $150 \mathrm{mbar}(14 \mathrm{~km})$. The upper panel of Fig. 5 presents residuals of least-squares fits to $1963 \mathrm{~cm}^{-1}$ window measurements from the clear sky occultations SS70, SS73, and SS76. Based on these results. we estimate a precision of $\pm 3 \%, 1 \sigma$, for the clear sky vs pressure reference curves in the upper troposphere and lower stratosphere. It was necessary to select $26^{\circ} \mathrm{N}-31^{\circ} \mathrm{N}$ latitude occultations for defining the filter 3 clear sky reference curves because of detectable upper tropospheric and/or lower stratospheric cloud attenuation at some altitudes in all of the tropical occultations. The lower panel of Fig. 5 presents the $1963 \mathrm{~cm}^{-1}$ window cloud transmittance profiles derived for occultations SS97, SS100, and SS106. The SS97 measurements show cloud extinction extending across the tropopause into the lower stratosphere. Hence, these observations represent an example of direct convective transport of upper tropospheric air into the lower stratosphere. The SS100 measurements show extinction by layered clouds at lower altitudes. The cloud transmittance decreased sharply to 0.2 at $200 \mathrm{mbar}(12.2 \mathrm{~km})$ followed by a recovery to 0.9 at $230 \mathrm{mb}(11.1 \mathrm{~km})$. Clear sky conditions occurred above 110 mbar $(15.9 \mathrm{~km})$ during $\mathrm{SS} 106$ with a sharp decrease to a cloud transmission $<0.1$ below 160 mbar $(13.3 \mathrm{~km})$.

Figure 6 presents cloud transmittances at 2661 and $3228 \mathrm{~cm}^{-1}$, normalized to the corresponding value at $1963 \mathrm{~cm}^{-1}$, plotted vs cloud transmittance at $1963 \mathrm{~cm}^{-1}$. Tropical measurements between tangent pressures of 50 and $200 \mathrm{mb}(12-20 \mathrm{~km}$ altitude) have been included. As demonstrated by this figure, upper tropospheric cloud extinction shows very little wavelength dependence in the 3-5 $\mu \mathrm{m}$ region, at least for the cases observed by ATMOS in the tropics and subtropics during the ATLAS 3 mission. In Fig. 7, Mie theory calculations of the extinction cross section for hexagonal ice are presented for the $800-4000 \mathrm{~cm}^{-1}$ region and particles with radii of $0.75,3,6$, and $12 \mu \mathrm{m}$. The strong $3 \mu \mathrm{m}$ extinction feature predicted for a particle radius of $0.75 \mu \mathrm{m}$ was not detected in any of the ATMOS upper tropospheric filter 3 tropical and subtropical observations. 


\section{ICE: CRYSTAL EXTINCTION CALCULATIONS}

Monochromatic optical depth ratios have been calculated for randomly oriented spheroidal ice crystals on the basis of the model of Takano et al. ${ }^{17}$ Following the nomenclature used in Ref. 17, the equivalent spherical radius of a spheroid may be expressed by

$$
a_{\mathrm{s}}=a_{\mathrm{e}}\left[v /\left(\cos ^{2} \zeta+\iota^{2} \sin ^{2} \zeta\right)^{1 / 2}\right]^{k 1} .
$$

where 5 is the angle between the incident direction and the rotation axis of the spheroid; $a_{\mathrm{s}}$ is the radius of the spheroid, i.e. the length of the short (long) se niaxis for prolate (oblate) spheroids; and $r$ is the axial ratio ( $>1$ for prolate spheroids, $<1$ for oblate spheroids). The extinction cross section of a spheroid may be expressed by

$$
C_{\mathrm{e}}(\zeta)=Q_{\mathrm{sph}} \pi a_{\mathrm{e}}^{2}\left[\left(\cos ^{2} \zeta+v^{2} \sin ^{2} \zeta\right)^{1 / 2}\right]^{k 2},
$$

where $Q_{\mathrm{sph}}$ is the optical efficiency factor from Mie theory for a sphere of radius $a_{\mathrm{s}}$. The empirical constants $k 1$ and $k 2$ in Eqs. (1) and (2) were determined as described in Ref. 17, where their numerical values are given. Finally, the extinction between cross section for randomly oriented spheroids is given by

$$
\bar{C}_{\mathrm{c}}=\int_{0}^{\pi / 2} C_{\mathrm{e}}(\zeta) \sin \zeta \bar{\zeta}
$$

The Takano et a $11^{17}$ model may be used as a first approxim: tion for spheroids whose area-equivalent size parameter, $x_{\mathrm{k}}=2 \pi r_{\mathrm{g}} / \mathrm{d}$ is less than $\sim 30$, with $a_{\mathrm{e}}$ and $v$ related to $r_{\mathrm{g}}$, the radius of the area-equivalent sphere, as given in Ref. 43. Area-equivaler t spheres are used because they produce the same optical depth as randomly oriented nonspherical particles. ${ }^{17}$

Calculations were performed with two sets of water ice optical constants as provided on the HITRAN 1996 CD ROM. ${ }^{+2}$ Imaginary indices of refraction in the compilation of Warren ${ }^{38}$ are based on spectral reflectance measurements of polycrystalline ice samples formed from the freezing of water at $266 \mathrm{~K}^{36}$ with corresponding real indices of refraction calculated from a Kramers-K ronig transform based on imaginary indices of refraction measured over a broad frequency range. The $163 \mathrm{~K}$ hexagonal ice optical constants of Toon $\mathrm{e} \mathrm{al}^{30}{ }^{39}$ were determined from thin film transmittances and an iterative Kramers Kronig technique. Differences among the reported infrared optical constants for $\mathrm{H}_{2} \mathrm{O}$ ice have been summarized by Toon et $\mathrm{al}^{39}$ except for the recent polycrystalline water ice optical constant measurements of Clapp et $\mathrm{al}^{40}(\mathrm{n} \cdot \mathrm{t}$ yet included in HITRAN), which cover $800-4000 \mathrm{~cm}{ }^{1}$ at nine temperatures between 130 and $210 \mathrm{~K}$. A strong temperature dependence of the IR optical constants is indicated by the Clapp et $\mathrm{al}^{40}$, latasets near the 3 and $12 \mu \mathrm{m}$ ice bands. The following behavior has been noted for $800-1200 \mathrm{~cm}^{-1}$, our primary region of interest, by comparing measured optical constants for 130 to $266 \mathrm{~K},{ }^{36.38 .40}$ As the temperature is lowered over this range, the imaginary index of refraction increases bel ow $1000 \mathrm{~cm}^{-1}$ with a maximum relative change of 2.0 at $945 \mathrm{~cm}^{-1}$, near the sharp peak in the ATMOS thin cirrus, small ice crystal spectrum in the lower panel of Fig. 1. Above $1000 \mathrm{~cm}^{-1}$, where mi imum values of the imaginary index of refraction occur due to weak absorption, a more com lex temperature dependence has been measured with values both higher and lower than at $266 \mathrm{~K}$; at $1050 \mathrm{~cm}^{-1}$, near the minimum of the imaginary index of refraction, values at the coldest tempers ture are more than a factor of two lower than at $266 \mathrm{~K}$. Ratios of the real index of refraction reach a maximum of 1.2 at $800 \mathrm{~cm}^{-1}$ with the higher values at $130 \mathrm{~K}$ relative to the $266 \mathrm{~K}$ measurements possibly due in part to truncation errors in the Kramers Kronig integrations. ${ }^{36.38 .40}$

Figure 8 presents the model-calculated optical depth ra ios plotted as a function of $r_{\mathrm{g}}$ for aspect ratios $v$ of 0.5 (oblate spheroid). 1.0 (sphere), and 2.0 (prolate spheroid). Differences in the $831 \mathrm{~cm}^{-1} / 957 \mathrm{~cm}^{-1}$ optical depth ratio calculated with the two sets of optical constants and the values of $v$ in the figure are up to $35 \%$ at $r_{\mathrm{g}}<1 \mu \mathrm{m}$ decli ing to $<14 \%$ for $5<r_{\mathrm{g}}<20 \mu \mathrm{m}$. The maximum difference in the $831 \mathrm{~cm}^{-1} / 1204 \mathrm{~cm}^{-1}$ optical d sth ratio is $11 \%$ with agreement to $5 \%$ or better for $r_{\mathrm{g}}>2 \mu \mathrm{m}$.

Figure 9 presents comparisons of the extinction ratics measured from the filter 12 tropical occultations with values calculated with the Warren ${ }^{38}$ and ${ }^{-}$oon et al ${ }^{34}$ optical constants. Error bars reflect uncertainties in the cloud transmittances of $\pm 5 \%$ at 831 and $957 \mathrm{~cm}^{-1}$ and $\pm 7 \%$ at $1204 \mathrm{~cm}^{-1}$ due to instrument noise, zero-level offsets in the spectral, and possible deviations of the 

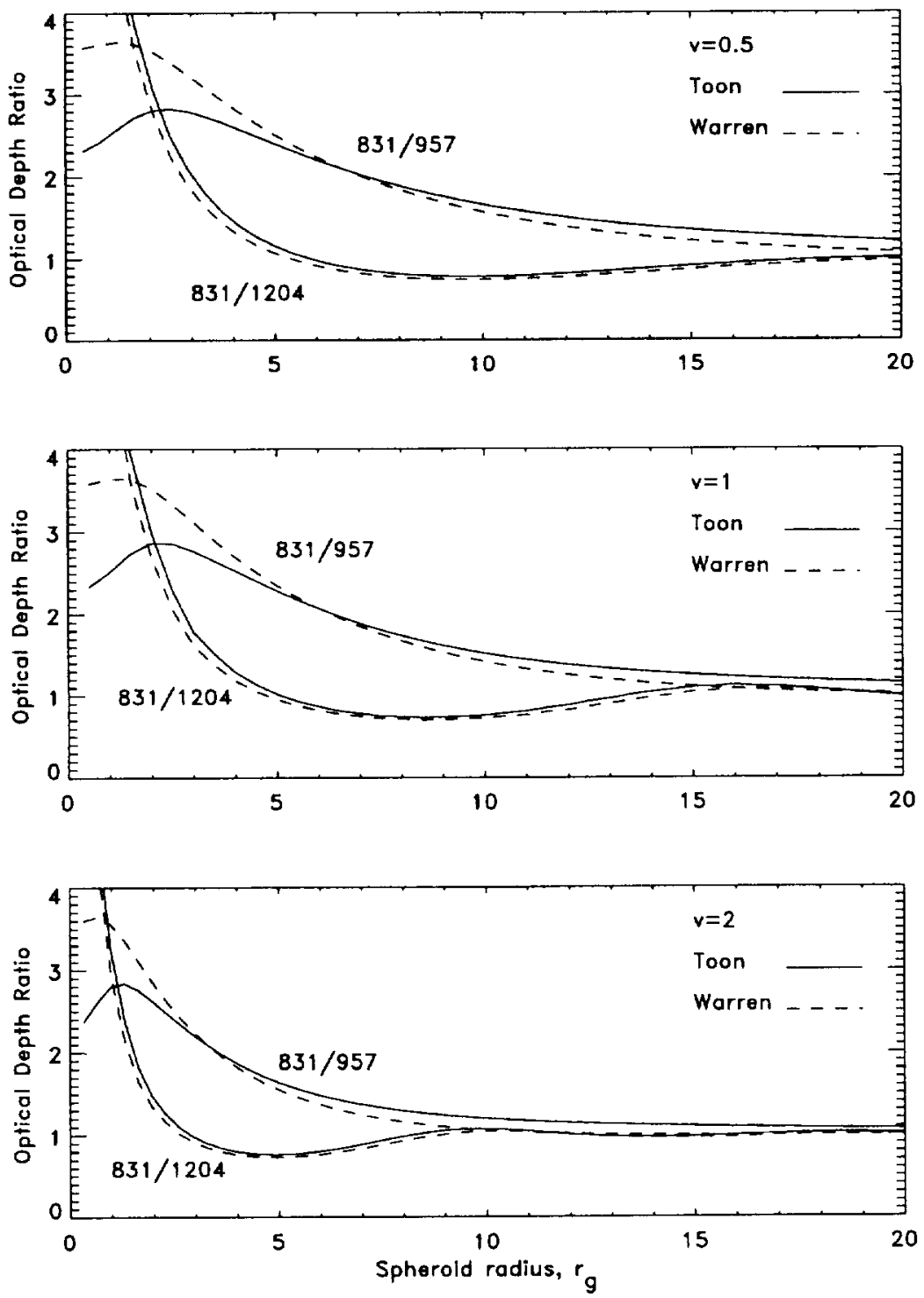

Fig. 8. Monochromatic optical depth ratios from calculated extinctions at 831,957 and $1204 \mathrm{~cm}^{-1}$, as a function of $r_{8}$, the radius of an area-equivalent sphere for spherical particles $(v=1.0)$ and spheroids $v=0.5,2.0)$. Curves labeled 831957 refer to ratios of the optical depth at $831 \mathrm{~cm}^{-1}$ to the value at $957 \mathrm{~cm}^{-1}$; similarly, curves labeled $831 / 1204$ refer to ratios of the optical depth at $831 \mathrm{~cm}^{-1}$ to the value at $1204 \mathrm{~cm}^{-1}$. Solid and dashed curves were computed with the hexagonal water ice optical constants of Warren ${ }^{38}$ and Toon et al, ${ }^{39}$ respectively.

measurements from the clear sky signal vs tangent pressure reference curve assumed for each micro window (e.g. Fig. 2). A larger error has been adopted for the cloud transmittance measurements at $1204 \mathrm{~cm}^{-1}$ than those at 831 and $957 \mathrm{~cm}^{-1}$ because of the stronger extinction observed at $1204 \mathrm{~cm}^{-1}$ and the uncertainty in its origin. The observations are in good agreement with the calculations, except for the measurements with EXT831/EXT957 $>1.5$. The highest EXT831/ EXT957 values of 1.8 correspond to a model $r_{\mathrm{g}}$ value of $\sim 6 \mu \mathrm{m}$, with only minor dependence on the $v$ parameter. As illustrated by the calculations in Fig. 8 , large $831 \mathrm{~cm}^{-1} / 957 \mathrm{~cm}^{-1}$ optical depth ratios are related to small crystals. The ATMOS data for the smallest crystals are within the range of 2-20 $\mu \mathrm{m}$ simulated by Jensen et $\mathrm{al}^{5}$ for mature clouds near the tropical tropopause. The larger measurement-calculation discrepancies for the small crystal observations may reflect the wide range of complex shapes often exhibited by ice crystals in cirrus clouds and the limitations inherent in 

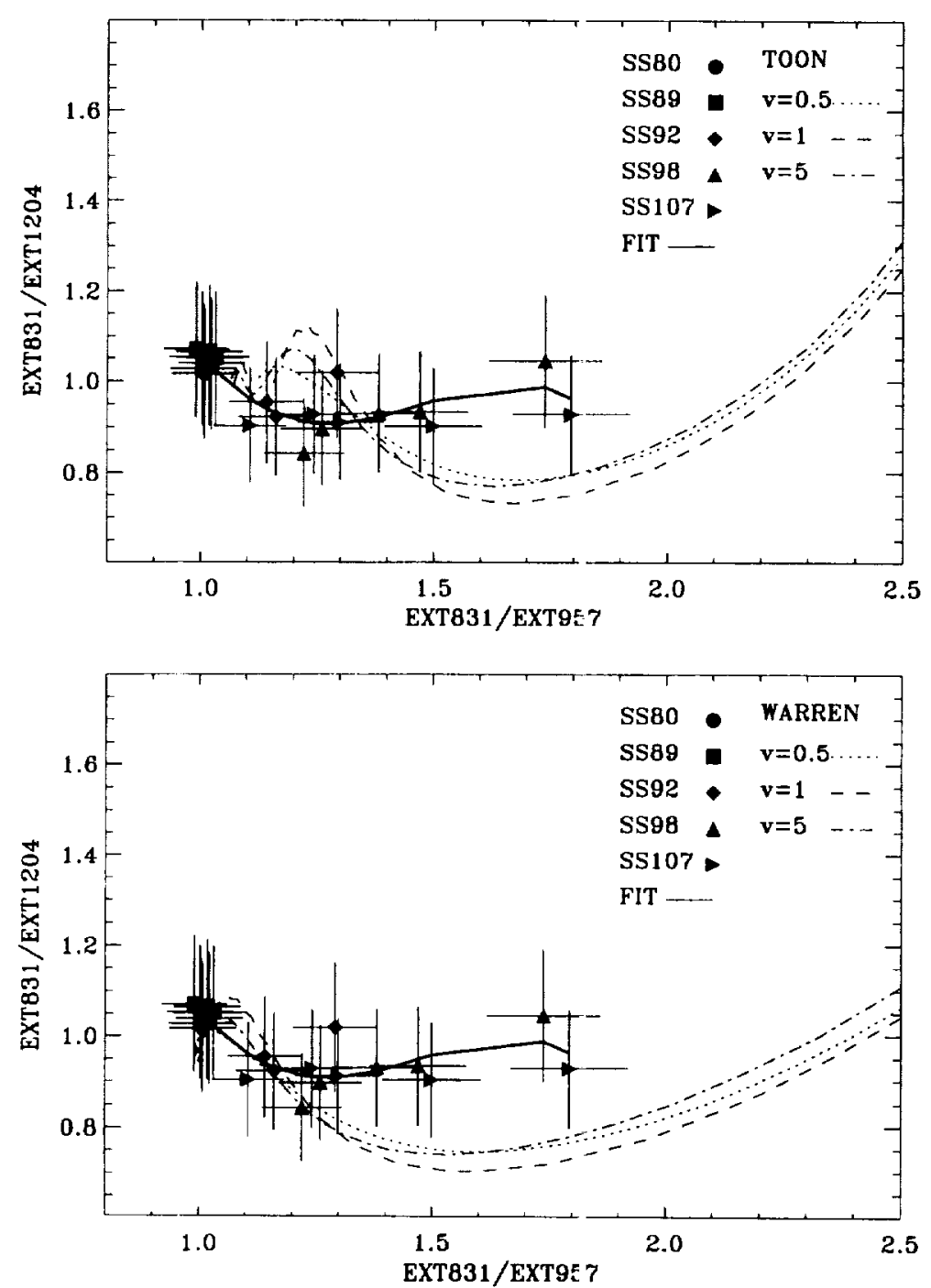

Fig. 9. Comparison between ATMOS ice extinction ratios at 831,957 and $1204 \mathrm{~cm}^{-1}$ and model-generated values obtained with the hexagonal ice optical constants of Toon et a $1^{39}$ (upper panel) and Warren ${ }^{38}$ (lower panel). Solid symbols and error bars show the individual measurements and their $1 \sigma$ uncertainties. Included observations were restricted to tangent pressures (heights) of $70-150 \mathrm{mbar}(14-18 \mathrm{~km})$ and ice transmittances between 0.05 and 0.95 to minimize the uncertainties.

assuming a single crystal size rather than a distribution of sizes in the model calculations. Based on the Mie theory calculations and the Toon et a ${ }^{16}$ ice opt cal constants, we infer from normalized extinction kernel calculations ${ }^{2}$ that the ATMOS 8-12 $\mu \mathrm{r}$ i spectra contain useful information on particle radii between about 1 and $30 \mu \mathrm{m}$ with good sensitivity in the range $2-10 \mu \mathrm{m}$, whereas the ATMOS 3-5 $\mu \mathrm{m}$ spectra contain useful information on crystals with radii between about $0.3-1.0 \mu \mathrm{m}$ and good sensitivity for particle radii between 0.4 and $4, \mathrm{~m}$.

Mie theory calculations assuming $6 \mu \mathrm{m}$ for the charact ristic radius of small ice crystals predict a strong spectral feature with extinction that increases by a factor of 2.8 from 3500 to $3660 \mathrm{~cm}^{-1}$ (see Fig. 7). Unfortunately, atmospheric transmission is low in that region due to strong absorption by $\mathrm{CO}_{2}$ lines and the strong $v_{1}$ band of $\mathrm{HNO}_{3}$, not included in the HITRAN 1996 database. ${ }^{44} \mathrm{~A}$ search for this characteristic ice feature in the ATMOS filter $4 \mathrm{spt} \operatorname{ctra}\left(3120-4750 \mathrm{~cm}^{-1}\right)$ was inconclusive because of the strong molecular interferences. A definitiv s search will require parameters for the $\mathrm{HNO}_{3} v_{1}$ band. 


\section{SUMMARY AND CONCLUSIONS}

In this paper, we have reported an initial analysis of cloud extinction measurements from $0.01 \mathrm{~cm}^{-1}$ resolution, broadband IR solar occultation spectra recorded in the tropical and subtropical upper troposphere and lower stratosphere by the ATMOS FTS during the ATLAS 3 shuttle mission of November 1994. Several occultations show wavelength-dependent ice extinction in the $8-12 \mu \mathrm{m}$ region due to large numbers of small ice crystals. None of the occultations observed with a filter covering $3-5 \mu \mathrm{m}$ show the $3 \mu \mathrm{m}$ ice band, which is a characteristic extinction feature of ice particles with radii $\leq 1 \mu \mathrm{m}$. Methods have been developed to retrieve cirrus extinction coefficient vertical profiles from measurements in narrow spectral intervals with minimal molecular absorption. The strength of this approach is that it allows us to take advantage of the high spectral resolution to avoid interfering lines and the multiple observations to define clear sky reference curves to accurately account for unmodeled extinction. Comparisons of our ATMOS 8-12 $\mu$ m cirrus extinction measurements with calculations for randomly-oriented spheroidal ice crystals indicate an area-equivalent spherical radius of about $6 \mu \mathrm{m}$ for the smallest observed ice crystals. Differences between the small particle extinction measurements and calculations performed with the hexagonal water ice optical constants of Warren ${ }^{38}$ and those of Toon et $a^{39}{ }^{39}$ imply the need for further study. Recent laboratory measurements ${ }^{40}$ show a strong temperature dependence for ice optical constants in the spectral regions used in this work and many previous remote-sensing cloud studies. ${ }^{11}{ }^{15-17,26-30}$ Hence, future 8-12 $\mu \mathrm{m}$ cloud investigations need to incorporate temperaturedependent optical constants in models of cirrus radiative properties and algorithms used to retrieve particle size distributions from atmospheric measurements. Further studies of the ATMOS cloud extinction measurements are in progress.

Acknowledgements--. Research at the Jet Propulsion Laboratory (JPL) was performed under contract to the National Aeronautics and Space Administration (NASA). Research at the University of Denver is supported by NASA and the National Science Foundation (NSF). Research at the University of Alabama was supported by NASA's Atmospheric Chemistry Modeling and Analysis Program. Research at Science and Technolngy Corporation (STC) and Science Applications International Corporation (SAIC) is also supported by NASA. The University of Liège involvement in the ATMOS project was partly supported by the Belgian "Global Change" program coordinated by the O.S.T.C., Brussels. We thank Linda Chiou of SAIC for her help in the analysis of the ATMOS spectra and the preparation of the figures. We are also grateful to Geoff Toon of JPL and Barney Farmer for helpful discussions, and we thank two anonymous referees for numerous, constructive comments.

\section{REFERENCES}

1. Prabhakara, C., Kratz, D. P., Yoo, J.-M., Dalu, G. and Vernekar, A., Optically thin cirrus clouds: radiative impact on the warm pool. JQSRT, 1993, 49, 467-483.

2. Wang, P.-H., McCormick, M. P., Poole, L. R., Chu, W. P., Yue, G. K., Kent, G. S. and Skeens, K. M.. Tropical high cloud characteristics derived from SAGE II extinction measurements. Atmos. Res., 1994. 34, 53-83.

3. Wylie, D. P., Menzel, W. P., Woolf, H. M. and Strabala, K. I., Four years of global cirrus cloud statistics using HIRS. J. Clim., 1994, 7, 1972-1986.

4. Wang, P.-H, Minnis, P., McCormick, M. P., Kent, G. S. and Skeens, K. M., A six year climatology of cloud occurrence frequency from stratospheric aerosols and gas experiment II observations (1985-1990). J. Geophys. Res., 1996, 101, 29 407-29 429.

5. Jensen, E. J., Toon, O. B., Selkirk, H. B., Spinhirne, J. D. and Schoeberl, M. R., On the formation and persistence of subvisible cirrus clouds near the tropical tropopause. J. Geophys. Res., 1996, 101, $21361-21375$.

6. Gage, K. S., McAfee, J. R., Carter, D. A., Ecklund, W. L., Riddle, A. C., Reid, G. C. and Balsley, B. B., Long-term mean vertical motion over the tropical pacific: wind-profiling Doppler radar measurements. Science, 1991, 254, 1771-1772.

7. Jensen, E. J., Toon, O. B., Pfister, L. and Serkirk, H. B., Dehydration of the upper troposphere and lower stratosphere by subvisible cirrus clouds near the tropical tropopause. Geophys. Res. Lett., 1996, 23, $825-828$

8. Borrmann, S., Solomon, S., Dye, J. E. and Luo, B., The potential of cirrus clouds for heterogeneous chlorine activation. Geophys. Res. Lett., 1996, 23, 2133-2136.

9. Solomon, S., Borrmann, S., Garcia, R. R., Portmann, R., Thomason, L., Poole, L. R., Winker, D. and McCormick, M. P., Heterogeneous chlorine chemistry in the tropopause region. J. Geophys. Res., 1997, 102, $21411-21429$.

10. Heymsfield, A. J., Ice particles observed in a cirriform cloud at $-83 \mathrm{C}$ and implications for polar stratospheric clouds. J. Atmos. Sci., 1986, 43, $851-855$. 
11. Heymsfield, A. J. and McFarquhar, G. M., High albedos of cirrus in the tropical pacific warm pool: Microphysical interpretations from CEPEX and from Kwajalein, Marshall Islands. J. Atmos. Sci., 1996, 53, 2424-2451.

12. Knolenberg, R. G., Kelly, K. and Wilson, J. C., Measuremen s of high number densities of ice crystals in the tops of tropical cumulonimbus. J. Geophys. Res., 1993, 98, 8639-8664.

13. Knollenberg, R. G., Dascher, A. G. and Huffman, D., Measurements of the aerosol and ice crystal populations in tropical stratospheric cumulonimbus anvils. Geophys. Res. Lett., 1982, 9, 613-616.

14. McFarquhar, G. M. and Heymsfield, A. J., Microphysical characteristics of three anvils sampled during the central equatorial pacific experiment. J. Atmos. Sci., 1996, 53, 2401-2423.

15. Baran, A. J., Brown, S. J., Foot, J. S. and Mitchell, D. L, Retrieval of tropical cirrus thermal optical depth, crystal size and shape using a multiview instrument at 3.7 and $10.8 \mu \mathrm{m}$. J. Atmos. Sci., 1998, in press.

16. Ou, S. C., Liou, K. N., Gooch, W. M. and Takano, Y., Remote sensing of cirrus cloud parameters using advanced very-high-resolution radiometer 3.70 and $10.9 \mu \mathrm{n}$. channels. Appl. Opt., 1993, 32, 2171-2180.

17. Takano, Y., Liou, K. N. and Minnis, P., The effects of small ice crystals on cirrus infrared radiative properties. J. Atmos. Sci., 1992, 49, 1487-1493.

18. Hanel, R. A., Conrath, B. J., Kunde, V. G., Prabhakara, C., Revah, I., Salomonson, V. V. and Wolford, G., The nimbus 4 infrared spectroscopy experiment 1 . Calibrat:d thermal emission spectra. J. Geophys. Res.. 1972, 77, 2629-2641.

19. Rinsland, C. P., Gunson, M. R., Wang, P.-H., Arduini, R. F., Baum, B. A., Minnis, P., Goldman, A., Abrams, M. C., Zander, R., Mahieu, E., Salawitch, R. J., Michelsen, H. A., Irion, F. W. and Newchurch, M. J., ATMOS/ATLAS 3 infrared profile measurements of trace gases in the November 1994 tropical and subtropical upper troposphere. JQSRT, 1998, this issue.

20. Farmer, C. B., High resolution infrared spectroscopy of the sun and earth's atmosphere from space. Mikrochim. Acta [Wien], 1987, III, 189-214.

21. Farmer, C. B., Raper, O. F. and O'Callaghan, F. G., Final report on the first flight of the ATMOS instrument during the Spacelab 3 mission, April 29 through May 6, 1985, JPL Publ. 87-32, 45pp., Jet Propulsion Laboratory, Pasadena, CA, 1 October 1987.

22. Kaye, J. A. and Miller, T. L., The ATLAS series of shuttle missions. Geophys. Res. Lett., 1996, 23, 2285-2288.

23. Gunson, M. R., Abbas, M. M., Abrams, M. C., Allen, M., Brown, L. R., Brown, T. L., Chang, A. J., Goldman, A., Irion, F. W., Lowes, L. L., Mahieu, E., Manney, G. L., Michelsen, H. A., Newchurch, M. J., Rinsland, C. P., Salawitch, R. J., Stiller, G. P., Toon, G. C, Yung, Y. L. and Zander, R. The atmospheric trace molecule spectroscopy (ATMOS) experiment: Deplo: ment on the ATLAS space shuttle missions. 1996. Geophys. Res. Lett. 23, 2333-2336.

24. Norton, R. H. and Rinsland, C. P., ATMOS data processing and science analysis methods. Appl. Opt., 1991, 30, $389-400$

25. Abrams, M. C., Chang, A. Y., Gunson, M. R., Abbas, M. M , Goldman, A., Irion, F. W., Michelsen, H. A., Newchurch, M. J., Rinsland, C. P., Stiller, G. P. and Zander, R., On the assessment and uncertainty of atmospheric trace gas burden measurements with high resolution infrared solar occultation spectra from space by the ATMOS experiment. Geophys. Res. Lett., 199i, 23, 2337-2340.

26. Smith, W. I., Ma, X. L., Ackerman, S. A., Rivercomb, H. E and Knuteson, R. O., Remote sensing cloud properties from high spectral resolution infrared observaticns. J. Atmos. Sci., 1993, 50, 1708-1720.

27. Ackerman, S. A., Smith, W. L., Spinhirne, J. D. and Rivercor 1b, H. E., The 27-28 October 1986 FIRE IFO cirrus case study: spectral properties of cirrus clouds in the $\varepsilon-12 \mu \mathrm{m}$ window. Mon. Weath. Rev., 1990, 118, 2377-2388.

28. Ackerman, S. A., Smith, W. L., Collard, A. D., Ma, X. L., Fivercomb, H. E. and Knuteson, R. O., Cirrus cloud properties derived from high spectral resolution inf ared spectrometry during FIRE II. Part II: aircraft HIS results. $J$. Atmos, Sci., 1995, 52, 4246 4263.

29. Strabala, K. I., Ackerman, S. A. and Menzel, W. P., Cloud properties inferred from 8-12 $4 \mathrm{~m}$ data. J. Appl. Meteorol. 1994, 33, 212-229.

30. Prabhakara, C., Yoo, J.-M., Dalu, C. and Fraser, R. S., Leep optically thin cirrus clouds in the polar regions. Part 1: infrared extinction characteristics. J. Appl. Aeteorol., 1990, 29, 1313-1329.

31. Rinsland, C. P., Yue, G. K., Gunson, M. R., Zander, R. an 1 Abrams, M. C., Mid-infrared extinction by sulfate aerosols from the Mt. Pinatubo eruption. JQSRT, 1994, 52, 241-252.

32. Toon, O. B. and Tolbert, M. A., Spectroscopic evidence agai ist nitric acid trihydrate in polar stratospheric clouds. Nature, 1995, 375, 218-221.

33. Kinne, S., Toon, O. B., Toon, G. C., Farmer, C. B., Browell, F. V. and McCormick, M. P., Measurements of size and composition of particles in polar stratospheric $\mathrm{cl}$ suds from infrared solar absorption spectra. J. Geophys. Res., 1989, 94, 16481-16491.

34. Fahey, D. W., Kelly, K. K., Ferry, G. V., Poole, L. P., Wilso 1, J. C., Murphy, D. M., Loewenstein, M. and Chan, K. R., In situ measurements of total reactive nitrogen, lotal water, and aerosol in polar stratospheric clouds in the antarctic. J. Geophys. Res., 1989, 94, 11299-1 315.

35. Abrams, M. C., Toon, G. C. and Schindler, R. A., Practical e cample of the correction of Fourier-transform spectra for detector nonlinearity. Appl. Opt., 1994, 33, 6307-6314. 
36. Schaaf, J. W. and Williams, D., Optical constants of ice in the infrared. J. Opt. Soc. Am., 1973, 63, 7267.32.

37. Bertie, J. E., Labbé, H. J. and Whalley, E., Absorptivity of ice in the range $400030 \mathrm{~cm} \quad$ '.J. Chem. Phys.. $1969, \mathbf{5 0}, 45014520$.

38. Warren, S. G., Optical constants of ice from the ultraviolet to the microwave. Appl. Opt., 1984, 23, $1206-1225$.

39. Toon, O. B., Tolbert, M. A., Koehler, B. G., Middlehrook, A. M. and Jordan, J., Infrared optical constants of $\mathrm{H}_{2} \mathrm{O}$ ice, amorphous nitric acid solutions, and nitric acid hydrates. J. Gophlys. Res., $1994,99$. $25631-25654$.

40. Clapp, M. L., Miller, R. E. and Worsnop. D. R., Frequency-dependent optical constants of water ice obtained directly from aerosol extinction spectra. J. Phis. Chem.. 1995, 99, 63176326.

41. Brown, L. R., Gunson, M. R., Toth, R. A., Irion, F. W., Rinsland, C. P. and Goldman. A., 1995 Atmospheric trace molecule spectroscopy (ATMOS) linelist. Appl. Opt., 1996, 35, 2828, 2848.

42. Rothman, L. S., Rinsland, C. P., Goldman, A.. Massie, S. T., Fdwards, D. P., Flaud, J.-M., Perrin, A. Dana, V., Mandin, J.-Y., Schroeder, J., McCann, A., Gamache, R. R.. Wattson, R. B., Yoshino, K., Chance, K., Jucks, K., Brown, L. R., Nemtchinov, V. and Varanasi, P., The HITRAN molecular spectroscopic database and HAWKS (HITRAN atmospheric workstation): 1996 edition. JQSRT, 1998, this issue.

43. Asano, S. and Sato, M., Light scattering by randomly oriented spheroidal particles. Appl. Opt., 1980. 19, 962-974.

44. Goldman, A., Rinsland, C. P., Perrin, A. and Flatud, J.-M., HNO 3 line parameters: 1996 HITRAN update and new results. JQSRT, 1998, this issue.

45. Gelman, M., National Meteorological Center, private communication, 1994. 
